\title{
Synchronous bilateral above knee amputation for gangrene resulting from bilateral compartment syndrome-a case report
}

\author{
Kadir Dotun $\mathrm{M}^{1 *}$, Fadimu Abidemi $\mathrm{A}^{2}$ and Nababa Mohammed $\mathrm{M}^{3}$ \\ ${ }^{1}$ Orthopedic unit, Department of Surgery, General Hospital, Ilorin, Nigeria \\ ${ }^{2}$ Orthopedic unit, Department of Surgery, Federal Medical Centre, Kebbi, Nigeria \\ ${ }^{3}$ Anesthesia Department, General Hospital, Ilorin, Nigeria
}

\begin{abstract}
Traditionally, most surgical procedures are carried out by one surgeon and assistant except when a second assistant is required and this is defined by the nature or indication for the operation and its technicalities. We present a $60 \mathrm{yr}$ old man who underwent synchronous bilateral above knee amputation.
\end{abstract}

\section{Introduction}

Significant numbers of major limb amputations are unilateral, usually in the lower limbs and more commonly below rather than above the knee. A small proportion of these amputations are bilateral which result from trauma or diabetic foot gangrene [1-3] It is stated that a diabetic patient with an amputated diabetic foot will undergo amputation of the contralateral limb in 2-3 years [4]. Trauma from road traffic crashes is a major reason a patient may undergo a bilateral amputation. In spite of the several articles on major limb amputations, [1,5-7] reports on synchronous bilateral major limb amputations are scarce.

We present a 60 year old male driver with bilateral lower limb gangrene as a result of compartment syndrome sustained from road traffic crash who had synchronous bilateral above knee amputation.

\section{Case report}

$\mathrm{AI}$ is a $60 \mathrm{yr}$ old male articulated trailer truck driver who presented to our centre 2 days following a road vehicular crash in which he had a head on collision with another stationary trailer during the night. The cabin of his trailer was crushed in the impact pinning both lower limbs in the wreckage. He sustained a deep laceration over the popliteal fossa of the left leg with some bleeding, no external injuries on the right leg and no loss of consciousness. He was later extricated from the vehicle and taken to a nearby hospital where his lacerations were sutured. On the second day on admission at the referral centre, both lower limbs were noted to be swollen, cold and painless prompting his referral to our centre. On presentation, he was conscious (GCS 15), not pale, afebrile and not dehydrated but pulse was $114 / \mathrm{min}$, respiratory rate was $16 / \mathrm{min}$, blood pressure of 100 systolic 60 diastolic. The left leg was swollen, cold to touch, non-tender but sensation was preserved. Sutured laceration over the popliteal fossa was noted with a distal based gangrenous skin patch measuring $10 \mathrm{~cm}$ by $8 \mathrm{~cm}$ which gave off a foul smelling discharge. There were crepitations in the soft tissue of the left calf extending to the distal thigh. The right leg was cold. There were no peripheral pulsations in both legs or movement observed below the knee.

A diagnosis of bilateral lower limb gangrene secondary to compartment syndrome with septic shock and gas gangrene was made. The sutured laceration over the popliteal fossa was released (Figure 1). A radiograph of the left leg confirms subcutaneous emphysema while there were no demonstrable fractures of any long bone. His packed cell volume was $24 \%$, white cell count was mildly elevated and differential count yielded a neutrophilia. Electrolytes and ECG were within normal limits. Wound swab microscopy, culture and sensitivity yielded mixed growth and sensitive to Levofloxacin. Intravenous fluids, broad spectrum antibiotics, analgesics, tetanus prophylaxis were started. $\mathrm{He}$ was transfused with 2 units of cross-matched and screened blood. An urgent Doppler ultrasound scan was ordered but could not be done due to financial constraints until the $3^{\text {rd }}$ day on admission which confirmed long segment occlusion at the level of the common femoral artery and vein on the left. There was a similar occlusion of the femoral artery \& vein at the adductor canal on the right. Fasciotomy was not considered because both limbs were already cold, had no pulsations and painless for over forty-eight hours after the incident. He was counselled for bilateral above the knee amputation but he refused. By the $4^{\text {th }}$ day gangrene was established and had ascended to the proximal third of the leg while there were multiple blisters with dark coloured fluid on the right leg (Figure 2). Consent was eventually given for the procedure.

${ }^{*}$ Correspondence to: Kadir Dotun M, Orthopedic unit, Department of Surgery, General Hospital, Ilorin, Nigeria, Tel: +234 (0) 802311 0989; E-mail: dotunk@yahoo.com

Key words: bilateral above knee amputation, major limb amputation, synchronous amputation, nigeria

Received: August 24, 2018; Accepted: August 28, 2018; Published: September 03,2018 
Synchronous bilateral above knee amputation was carried out under epidural block in the normal fashion by two teams of surgeon and assistant on each side as shown in figure 3. Surgery lasted $1 \mathrm{hr}$ 40mins. Hypotensive anesthetic technique and judicious use of diathermy were employed to reduce blood loss. He had 2 units of blood transfused intra-op and the intra-operative blood loss was estimated at approximately $350 \mathrm{mls}$.

The post-operative period was grossly uneventful except for a postoperative PCV of $24 \%$ which necessitated transfusion of two units of blood and superficial surgical site infection (SSSI) on the left stump which eventually healed (Figure 4). Patient was discharged home on a wheelchair after some physiotherapy sessions while the process for procuring prosthesis were on going.

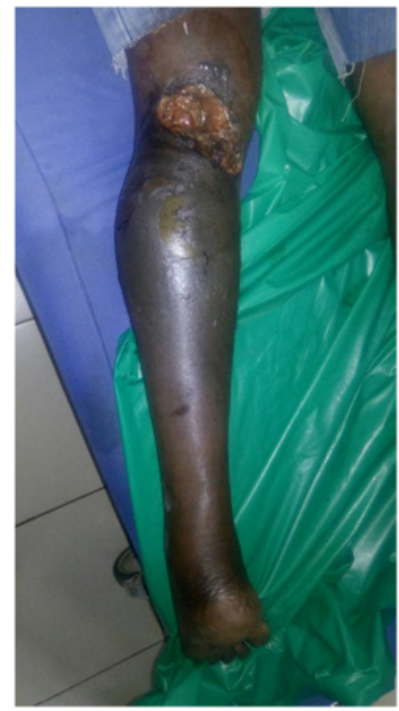

Figure 1. Posterior aspect of the left lower limb with laceration over the popliteal fossa and gangrene of the leg



Figure 2. Anterior aspect of the right leg and foot showing slough and blisters

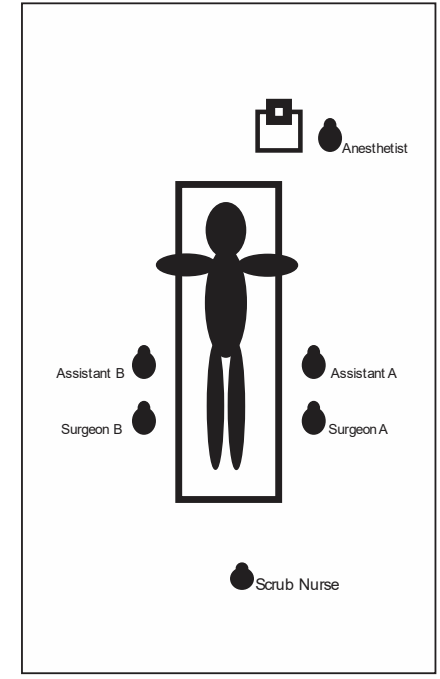

Figure 3. Positions of both surgical teams in relation to the patient, anesthesia and scrub nurse

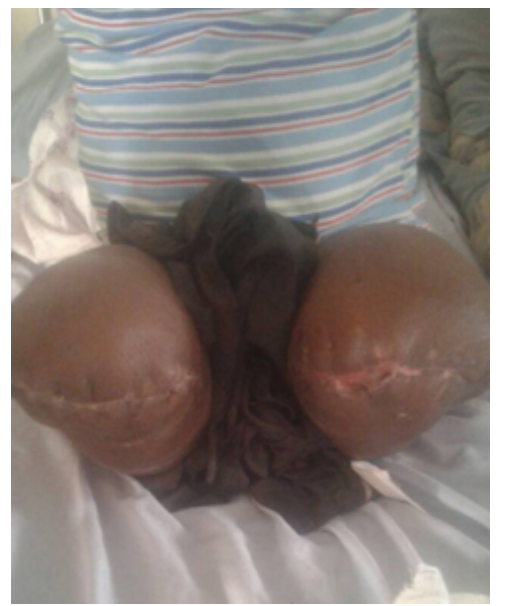

Figure 4. Post op status of both stumps with dehiscence of the left wound

\section{Discussion}

Traditionally, surgical procedures are carried out by a team of surgeon and assistant, each standing on either side of the patient. Occasionally, there is a need for a second assistant who stays on either side of the patient as needed by the surgeon. This is also true for major limb amputations either unilateral or bilateral. For bilateral amputations, these are carried out one limb after the other either in the same sitting or on different days. The reasons for this could be as a result of experience of the surgeon, non-availability of support staff and facilities, financial constraints and condition of the patient.

In our practice, significant numbers of our patients requiring major limb amputations are unilateral, bilateral amputations are rare and in both cases, a team of surgeon and assistant is utilised. The few bilateral amputations that have been done had several months or years in between both procedures. In a study in Tanzania of 162 patients and 53 patients in Ilorin, there were no bilateral amputations $[5,6]$. Road traffic crashes are still the commonest form of trauma resulting in major limb amputations in our environment [6]. Our patient developed compartment syndrome following trauma and developed gangrene in both lower limbs. In this case we decided to carry out bilateral above knee amputations synchronously for the following reasons, financial 
constraints, poor vis-à-vis anticipated worsening clinical state of the patient, competition for theatre space in between other non-orthopedic emergencies and also to reduce the expected long duration of surgery had the procedure been carried out one limb after the other. The long duration of surgery also exposes the patient the risk of excessive blood loss, hypotension and infection. The duration of surgery was $1 \mathrm{hr} 40 \mathrm{mins}$ which is much shorter if carried out one after the other. Though there is no set duration for carrying out an amputation due to several factors, Kinugawa and Shimada in Japan spent $70 \mathrm{mins}$ for an above knee amputation [8]. This shows that the duration of surgery would have been longer if carried out one after the other. Although we didn't use a tourniquet, judicious use of diathermy kept blood loss to a minimum. Intra-operative blood loss was $350 \mathrm{mls}$ which slightly lower but similar to that found by Wied, et al. [9]. Other reasons to do a synchronous procedure include the risk of the anesthesia wearing off and necessitating a conversion to general anesthesia and surgeon's fatigue.

For this synchronous procedure to be done, the following are essential; appropriate patient selection (there should not be any underlying cardiac condition), availability of experience personnel, monitoring equipment and blood banking services which were all present.

Positioning of both teams can be seen in the illustration in Figure 3. Both surgeons are positioned distally while the assistants are proximal. This was beneficial as the assistants are able to retract tissues without crossing their hands or the surgical field. The use of the single diathermy did not cause any problems or confusion as anticipated. The scrub nurse was positioned at the foot of the operating table where she could comfortably see both surgeons and pass needed instruments as needed.

\section{Conclusion}

Performing a synchronous bilateral above knee amputation reduces operating time, prolonged exposure to anesthesia, and intra operative bleeding. Requirements for a favourable outcome include proper planning, patient selection, availability of experienced surgeons, anesthetist, facilities for patient monitoring and blood banking services.

\section{References}

1. Chikwendu Nwosu, Misbau O Babalola, Muhammed H Ibrahim, Siyaka I Suleiman (2017) Major limb amputation in a tetiary hospital in North Western Nigeria. Afr Health Sci 17: 508-512

2. Mamuda AA, Salihu MN, Abubakar MK, Adamu KM, Ibrahim M, et al. (2014) Profile of Amputations in National Orthopaedic Hospital, Dala, Kano. Open J Orthop 4: 200204

3. Baidoo RO, Debrah S (2016) Majot Limb Amputation: The Koforidua Experience. Postgrad Med J Ghana 5: 68-70.

4. Pasquina PF, Miller M, Carvalho AJ, Corcoran M, Vandersea J, et al. (2014) Special Considerations for Multiple Limb Amputation. Curr Phys Med Rehabil Rep 2: 273289. [Crossref]

5. Chalya PL, Mabula JB, Dass RM, Ngayomela IH, Chandika AB, et al. (2012) Major limb amputations: a tertiary hospital experience in northwestern Tanzania. J Orthop Surg Res 7: 18. [Crossref]

6. Kadir DM (2018) Indications and Early Post-Operative Complications of Major Limb Amputations in University of Ilorin Teaching Hospital, Ilorin. Trop J Health Sci 25: 53-58.

7. Odatuwa-Omagbemi DO (2014) Pattern of Limb Amputations in Male Patients in a Nigerian Teaching Hospital. IOSR-JDMS 13: 42-45.

8. Kinugawa H, Shimada Y (2014) A case of above knee amputation with preoperative high risks. J Rural Med 9: 90-92. [Crossref]

9. Wied C, Tengberg PT, Kristensen MT, Holm G, Kallemose T, et al. (2017) Total Blood Loss After Transfemoral Amputations Is Twice the Intraoperative Loss: An Observational Cohort Study of 81 Nontraumatic Amputations. Geriatr Orthop Surg Rehabil 8: 123-127.

Copyright: (C2018 Kadir Dotun M. This is an open-access article distributed under the terms of the Creative Commons Attribution License, which permits unrestricted use, distribution, and reproduction in any medium, provided the original author and source are credited. 